\title{
Advertising and Product Launch Strategies in the light of Tobacco Advertising \\ Legislation*
}

\author{
Caroline Elliott ${ }^{\#}$ \\ Lancaster University \\ and \\ Pamela Lenton \\ University of Sheffield
}

\begin{abstract}
This short paper aims to increase understanding of tobacco companies' advertising strategies. Time series data and intervention analysis methods are used to investigate whether tougher tobacco advertising legislation, and the threat of such legislation, result in firms significantly changing their advertising activities in the period preceding the enactment of legislation. The paper considers legislation introduced by both the UK Government and the EC in recent years. Results suggest that there is some significant short-term increase in advertising behaviour, coinciding with product launches that firms instigate prior to legislation changes. However, firms do not generally maintain higher advertising expenditures than previously throughout the period between legislation being introduced and coming into force.
\end{abstract}

\section{Introduction}

Many factors have been identified as potentially affecting demand for tobacco and cigarettes, including price, income, taxes, anti-smoking campaigns, advertising and advertising bans. Stewart (1993), Bardsley and Olekalns (1999), Saffer and Chaloupka (2000), Gallet (2003), and Nelson (2003) provide recent contributions to this literature. This paper instead focuses attention on the factors determining tobacco companies' advertising strategies, as despite the extensive literature on the effect of advertising on tobacco consumption, there remain relatively few studies that discuss

\footnotetext{
* The authors would like to thank seminar participants at Lancaster, Liverpool and Heriot-Watt Universities, and Gill Silverman of the Tobacco Manufacturers Association. The research was funded by a Nuffield Foundation Grant, ref. No. SGS/00935/A.

\# Author for correspondence. Department of Economics, Lancaster University Management School, Lancaster University, Lancaster, LA1 4YX. Tel. (01524) 594225 Fax (01524) 594244 C.Elliott@lancaster.ac.uk
} 
the factors determining these strategies. Bird (2002) estimates the relationship between tobacco companies' advertising expenditure and market share, whilst Hu et al. (1995) present an analysis of the tobacco industry advertising response to Californian state legislative changes. However, their analysis suffers as they were unable to obtain data on advertising expenditure. Meanwhile, Anderson et al. (2002) provide an overview of tobacco companies' broad marketing activities, whilst Chaloupka et al. (2002) focus on price related marketing strategies, and Depkin II (1999) examines the impact of advertising restrictions on cigarette prices.

This short paper contributes to the literature by summarising results of a research project investigating the implications of tougher tobacco advertising restrictions on tobacco companies' advertising strategies. Specifically, does tougher legislation and the threat of such legislation result in firms significantly changing their advertising activities in the period preceding the enactment of the legislation? In recent years there has been greater interest in the impact of threats on firms' behaviour. In the theory of contestable markets the threat of entry into a market by a potential rival forces incumbent firms to produce efficiently and to price their goods competitively. Further, in the absence of competitive pressures theoretical research, including papers by Klevorick (1973), Bawa and Sibley (1980), Logan et al. (1980) and Glazer and McMillan (1992), has shown that firms may maintain prices lower than otherwise be expected if the firms are concerned about the threat of price regulation or rate-ofreturn regulation. Empirical studies have also concluded that the threat of price regulation has a negative impact on firms' prices in a variety of industries, see for example Taylor and Zona (1997), Zweifel and Crivelli (1996), Acutt et al. (2001). Hence, this paper also extends the literature on regulation and regulatory threats by investigating the impact on firms' strategies of threatened advertising legislation as opposed to price regulation. The analysis is of particular interest as the paper investigates whether the threat of advertising legislation may induce a short-run increase in tobacco advertising, i.e. behaviour undesired by governments, whilst the threat of price regulation has been found both theoretically and empirically to induce lower prices, behaviour desired by the relevant regulator.

This research is timely as the UK Government's 2002 Tobacco Advertising and Promotion Act and the European Commission's 2001 Directive on Tobacco 
Advertising and Sponsorship both represent measures to restrict further the advertising of tobacco products. These follow earlier unsuccessful efforts by the UK Government and the European Commission (EC) to limit tobacco advertising in the late 1990s. An attempt by the EC to introduce tougher tobacco advertising restrictions (EC Directive 98/43/EC) was rejected by the European Court of Justice in 2000. Meanwhile, the UK Government published regulations in June 1999 that it intended to enforce from December 1999 in line with the EC Directive. However, the implementation of these regulations was postponed pending the European Court of Justice's decision regarding Directive 98/43/EC. Nevertheless, it should be borne in mind that in the UK at least, for a number of years the Tobacco Manufacturers Association (TMA) has negotiated a voluntary agreement with the Government, limiting firms' advertising expenditures, and adhering to rules, for example, regarding the size of printed tobacco advertising, and advertising near schools.

The analysis aims to test statistically whether tobacco firms do increase advertising prior to an advertising ban being implemented, as there is some documentation from the industry suggesting this is true. For example, Gallaher is reported by Tylee (2003) to have spent $£ 2.5$ million advertising the launch of a new brand of cigarette in the last few days before the main provisions of the 2002 Tobacco Advertising and Promotion Act came into force on February $14^{\text {th }}, 2003$. Similarly, Imperial Tobacco's Lambert and Butler brand had a large advertising campaign at this time, notifying consumers about the forthcoming advertising ban, Kleinman (2003). Results suggest that there is some significant short-term increase in advertising behaviour, coinciding with product launches that firms instigate prior to legislation changes. However, firms do not generally maintain higher advertising expenditures than previously throughout the period between legislation being introduced and coming into force.

\section{Data and Preliminary Analysis}

Nominal monthly tobacco advertising data (1993-2003) were supplied by Neilsen Media Research. These industry level data represent UK cigarette, cigar and tobacco advertising expenditure, plus corporate tobacco advertising expenditure, i.e. nonbrand specific advertising by tobacco companies, but not sponsorship expenditure. It should be noted that some of this expenditure is not prohibited under the 2002 UK Tobacco Advertising and Promotion Bill, which relates specifically to the advertising 
of tobacco products rather than advertising the firms who produce cigarettes, cigars and tobacco under various brand names. Advertising data were converted into real values using the all item RPI (1987=100), as found on Statbase. ${ }^{1}$

From casual observation of monthly real UK tobacco advertising data in Figure 1, it appears that there was a dramatic increase in advertising expenditure in the fourth quarter of 1999 prior to the European Court of Justice's 2000 rejection of the EC tobacco advertising directive. Then, whilst advertising levels were typically lower than previously after 2000, there was a short period of relatively high advertising expenditure prior to the UK advertising ban coming into force on February $14^{\text {th }} 2003$.

\section{Figure 1: UK Tobacco Advertising Expenditure}

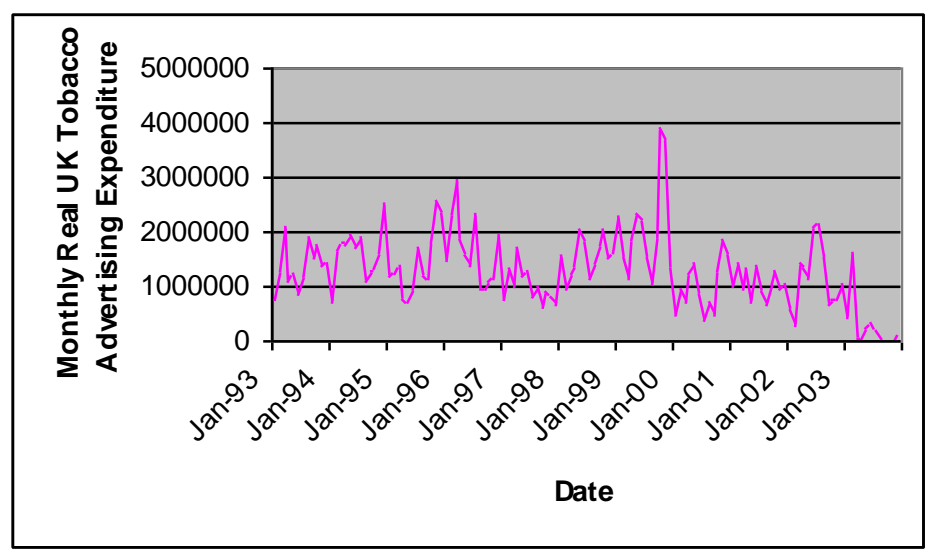

Source: Neilsen Media Research

A more rigorous method of testing the impact of legislation and future expected legislation on firms' advertising strategies is to use time-series intervention analysis. This technique allows for a formal test of a change in the mean of a time series. We use the procedure outlined in Enders (2004). Augmented Dickey-Fuller (ADF) and Phillips-Perron unit-root tests confirmed that the data were stationary, whilst Autoregressive Integrated Moving Average (ARIMA) modelling indicated that the data followed an autoregressive process with just the first and fourth lags being significant, with no significant moving average component. ${ }^{2}$ We deliberately restricted the number of explanatory variables to the intervention dummies and the relevant lagged dependent variables as we were interested in the impact of specific

\footnotetext{
${ }^{1}$ http://www.statstics.gov.uk/

${ }^{2}$ Please contact the corresponding author for full details of results.
} 
public policy changes on tobacco advertising levels. The research project is not an attempt to model the multiple factors that influence tobacco advertising strategies. Hence, the inclusion of additional explanatory variables, possibly to control for the impact of the strength of the economy on advertising levels, seemed unnecessary. Extra explanatory variables would have reduced the number of degrees of freedom in the statistical analysis, and whilst their inclusion may be expected to increase the explanatory power of the models, they were not expected to change significantly the results presented below. ${ }^{3}$

A number of intervention dummy variables were considered, with Table 1 below providing summary information on these variables.

\section{Table 1: Intervention Dummy Variables}

\begin{tabular}{l|l}
\hline Dummy Variable & Dates with dummy $=1$ \\
\hline D1 & $3 / 2003-12 / 2003$ \\
D2 & $2 / 2003$ \\
D3 & $4 / 2002-2 / 2003$ \\
D4 & $6 / 2002-2 / 2003$ \\
D5 & $7 / 1999-12 / 1999$ \\
D6 & $10 / 1999$ \\
D7 & $8 / 1998-10 / 2000$ \\
\hline
\end{tabular}

Variable D1 was required as inspection of Figure 1 indicated that, as expected, tobacco advertising levels fell to almost zero after the 2002 Tobacco Advertising and Promotion Act came into force. D2 was introduced to test if advertising expenditures changed significantly in the first two weeks of February 2003 before the 2002 Act became operational, whilst D3 and D4 were used to test if tobacco advertising increased in the period between the legislation being approved and becoming effective. D4 allows time for the firms to react and alter their advertising strategies after the legislation had been approved. D5 corresponds to the period in 1999 between when the UK Government announced regulations in line with EC Directive 98/43/EC and the intended imposition of the regulations. Dummy variable D7 relates

\footnotetext{
${ }^{3}$ It should also be noted that because of measurement difficulties, only quarterly data and not monthly data for potential control variables such as Gross Domestic Product (GDP) are produced.
} 
to the period between the EC proposing Directive 98/43/EC and European Court of Justice rejecting it, whilst, as to be discussed below, D6 relates to the month in which Imperial Tobacco launched its Richmond brand, increasing advertising to support the launch.

\section{Intervention Analysis of Advertising and Product Launch Strategies}

Analysis focused on the full dataset of 132 observations, for tobacco advertising as a whole. Initially, time-series regressions were used to test whether tobacco advertising expenditure changed (increased) significantly in the periods between UK and EC legislation being introduced, and either being rejected by the European Court of Justice, or becoming effective in the case of the UK 2002 legislation.

Interestingly, the results in Table 2 suggest that whilst, as expected, the coefficient on dummy variable D1 is negative at all reasonable significance levels, indicating that tobacco advertising fell significantly after the 2002 Act came into force, the coefficients on the dummy variables D3 and D7, or D4 and D7 are never significant. Similarly, in comparable regressions with intervention dummy variable D7 replaced by D5, the coefficient on D5 is not significant. ${ }^{4}$ These results indicate that the tobacco industry as a whole did not significantly increase advertising in the face of expected future tightened advertising restrictions, irrespective of whether the regulations were introduced by the UK Government or the EC. Yet this may have been the rational strategy to adopt given existing evidence regarding the impact of advertising on tobacco consumption that indicates that advertising only has a limited impact on demand, for example Gallet (2003) and Duffy (1995).

\footnotetext{
${ }^{4}$ These regression results are not presented for reasons of brevity but are available on request.
} 
Table 2 The Impact of Expected Legislation

\begin{tabular}{l|llll}
\hline Variable & Coefficient & $\mathrm{p}$-value & Coefficient & $\mathrm{p}$-value \\
\hline constant & 601700.5 & 0.001 & 597768.5 & 0.001 \\
real advertising (1) & 0.442 & 0.000 & 0.442 & 0.000 \\
real advertising (4) & 0.116 & 0.204 & 0.117 & 0.202 \\
$\mathrm{D} 1$ & -663919.1 & 0.000 & -660623.8 & 0.000 \\
$\mathrm{D} 3$ & -50257.6 & 0.766 & & \\
$\mathrm{D} 4$ & & & -40830.5 & 0.842 \\
$\mathrm{D} 7$ & 68025.0 & 0.626 & 69568.5 & 0.618 \\
$R^{2}$ & 0.436 & & 0.436 & \\
$\bar{R}^{2}$ & 0.413 & & 0.413 & \\
LM (4) & 4.049 & 0.399 & 3.743 & 0.442 \\
$\mathrm{~F}$ & 18.862 & 0.000 & 18.848 & 0.000 \\
$\mathrm{~N}$ & 128 & & 128 & \\
\hline
\end{tabular}

Note that the number of lags is given in parentheses in column 1.

LM denotes the Lagrange Multiplier test statistic for serially correlated residual terms. $\mathrm{N}$ denotes the number of observations used.

The p-values associated with the coefficient estimates all reflect White's heteroscedasticity adjusted standard errors as diagnostic testing indicated that the OLS residuals were characterised by heteroscedasticity.

Analysis continued in an attempt to model and understand the peaks in advertising expenditure that occurred in Autumn 1999 and February 2003, with results reported in Table 3. 
Table 3 Advertising and Product Launches

\begin{tabular}{l|ll}
\hline Variable & Coefficient & p-value \\
\hline constant & 608979.4 & 0.001 \\
Real advertising (1) & 0.442 & 0.000 \\
Real advertising (4) & 0.101 & 0.222 \\
D1 & -664045.0 & 0.000 \\
D2 & 739341.9 & 0.000 \\
D6 & 2234431.0 & 0.000 \\
$R^{2}$ & 0.526 & \\
$\bar{R}^{2}$ & 0.507 & \\
LM & 1.123 & 0.891 \\
F & 27.070 & 0.000 \\
$\mathrm{~N}$ & 128 & \\
\hline Note &
\end{tabular}

Note that the p-values associated with the coefficient estimates again all reflect White's heteroscedasticity adjusted standard errors as diagnostic testing indicated that the OLS residuals were characterised by heteroscedasticity.

The intervention dummies D2 and D6 are each positive and significant at all reasonable significance levels indicating significant increases in advertising expenditure in February 2003 and October 1999. The results in Table 2 indicated that advertising expenditures did not respond to the threat of a European tightening of tobacco advertising legislation in the full period up to the European Court of Justice's rejection of the legislation in 2000, and that similarly UK tobacco advertising expenditure did not increase significantly during the period between the UK Tobacco Advertising and Promotion Bill being passed and coming into force. Nevertheless, the coefficients on the intervention variables D2 and D6 indicate that UK tobacco advertising increased significantly in two particular months.

The increase in advertising in October 1999 reflects the introduction and roll out of the Richmond brand by Imperial Tobacco in September 1999, and Project Dolphin documentation indicates that the brand launch was brought forward so that brand advertising could be carried out prior to the planned ban on UK advertising in December 1999. 
"In an ideal scenario, we would probably have launched Richmond in January or February 2000. However, as you are aware, the Government plans to ban all advertising and promotions by $10^{\text {th }}$ December 1999 . Consequently, we have rushed the launch forward to $1^{\text {st }}$ September 1999."

http://www.tobaccopapers.com

Similarly, Tylee (2003) reported that:

"Gallaher is blitzing $£ 2.5$ million in nine days on a campaign to launch a new cigarette in what will be the last Benson and Hedges ad to be seen in Britain. The campaign, for Benson \& Hedges Silver, is being rushed out in advance of the tobacco ad ban beginning on 14 February, meaning that ads will appear before the product is available."

Hence, whilst tobacco industry advertising as a whole does not appear to be affected by the threat of future advertising legislation, individual firms' product launch and associated advertising strategies do seem to have been affected.

\section{Discussion and Conclusions}

At first sight, the results above may seem surprising. In the face of future additional tobacco advertising restrictions, firms may have been expected to increase advertising in the period prior to tougher legislation becoming effective. However, in light of the existing literature, some of which suggests that the impact of tobacco advertising on consumer demand may be minimal, the general strategy adopted of not increasing advertising expenditure significantly may be rational. Firms do not seem to have been panicked into increasing their advertising expenditures prior to tougher advertising bans being imposed. Nevertheless, if when faced with greater advertising restrictions, firms are already considering the introduction of a new brand, the evidence above indicates that these firms brought forward product launches so that extensive advertising could be undertaken prior to advertising bans coming into force. Again, this may be a sensible strategy to adopt if new products enjoy relatively high advertising elasticities of demand in comparison to mature products. The advertising of new products can then be expected to result in market share shifts in favour of the new products. This strategy could be interpreted as reflecting tobacco companies' claims that they use advertising to compete against rivals rather than to increase demand for tobacco/cigarettes as a whole. 
Although we conclude that the advertising strategies adopted by the tobacco companies in the face of tougher future advertising restrictions seem sensible, the public policy implications of the above results also need to be considered. If governments seek to ban or minimise tobacco advertising then the length of time between the announcement of legislation and the date when any legislation passed becomes effective should also be minimised. Although our results suggest that the tobacco industry as a whole may not significantly increase advertising expenditures prior to additional advertising restrictions being imposed, significant additional advertising of new products has been identified. Alternatively, governments may wish to consider restricting the number of new products entering the cigarette market in the period between legislation being introduced and coming into force. However, this may be difficult to achieve, and raises issues regarding the extent to which governments should restrict firms' strategies. Governments must also consider the breadth of advertising restrictions in the face of suggestions that tobacco firms continue to promote products in the face of advertising bans. "BWM's advertising brief for Imperial was for 'below the line' marketing activity, including point of sale material, packaging, events management, and relationship marketing.”, Harper (2001).

This research presents an attempt to increase understanding of tobacco companies' advertising strategies. It is intended that future research will develop this analysis through the use of firm level data. This will provide not only the ability to compare competing firms' advertising strategies in the face of tobacco advertising legislation, but will also permit the use of panel data regression techniques on a much larger dataset. Research is also still required to understand tobacco firms' international marketing strategies in the face of tougher advertising legislation in the UK, the EC and as an increasing number of countries sign up to the 2003 World Health Organization Framework Convention on Tobacco Control. 


\section{Bibliography}

Acutt, M., Elliott, C. and Robinson, T. (2001) 'Credible Regulatory Threats', Energy Policy, 29, pp.911-916.

Anderson, S., Hastings, G. and MacFadyen, L. (2002) 'Strategic Marketing in the UK Tobacco Industry', The Lancet Oncology, 3, pp. 481-486.

Bardsley, P. and Olekalns, N. (1999) 'Cigarette and Tobacco Consumption: Have Anti-Smoking Policies made a Difference', Economic Record, 75(230), pp. 225-240.

Bawa, V. S. and Sibley, D. S. (1980) 'Dynamic Behaviour of a Firm subject to Stochastic Regulatory Review’, International Economic Review, 21, pp.627-642.

Bird, K. (2002) 'Advertise or Die: Advertising and Market Share Dynamics Revisited', Applied Economics Letters, 9(12), pp. 763-767.

Chaloupka, F. J., Cummings, K. M., Morley, C. P. and Horan, J. K. (2002) 'Tax, Price and Cigarette Smoking: Evidence from the Tobacco Documents and Implications for Tobacco Company Marketing Strategies', Tobacco Control, 11 (Suppl 1), pp. 162-172.

Depkin II, C. A. (1999) 'The Effects of Advertising Restrictions on Cigarette Prices: Evidence from OECD Countries', Applied Economics Letters, 6, pp. 307-309.

Duffy, M. (1995) 'Advertising in Demand Systems for Alcoholic Drinks and Tobacco: a comparative study', Journal of Policy Modelling, 17, pp. 557-577.

Enders, W. (2004) Applied Econometric Time Series, second edition, New Jersey, USA, Wiley.

Gallet, C. A. (2003) 'Advertising and Restrictions in the Cigarette Industry: Evidence of State-by-State Variation', Contemporary Economic Policy, 21(3), pp. 338-348. 
Glazer, A. and McMillan, H. (1992) 'Pricing by the Firm under Regulatory Threat', Quarterly Journal of Economics, 107, pp.1089-1099.

Harper, T. (2001) 'Marketing Life after Advertising Bans', Tobacco Control, 10, pp.196-198.

Hu, T.-W., Sung, H.-Y. and Keeler, T. E. (1995) 'The State Antismoking Campaign and the Industry Response: The Effects of Advertising on Cigarette Consumption in California', American Economic Review Papers and Proceedings, 85(2), pp. 85-90.

Kleinman, M (2003) 'Imperial Informs Public of Ad Ban', Marketing, $6{ }^{\text {th }}$ February, 2.

Klevorick, A. K. (1973) 'The Behaviour of a Firm subject to Stochastic Regulatory Review', Bell Journal of Economics and Management Science, 4, pp.57-83.

Logan, J. W., Masson, R. T. and Reynolds, R. J. (1989) 'Efficient Regulation with Little Information: reality in the limit?', International Economic Review, 30, pp.851861.

Nelson, J. P. (2003) 'Cigarette Demand, Structural Change, and Advertising Bans: International Evidence, 1970-1995', Contributions to Economic Analysis and Policy, 2(1), www.bepress.com

Saffer, H. and Chaloupka, F. (2000) 'The Effect of Tobacco Advertising Bans on Tobacco Consumption', Journal of Health Economics, 19, pp. 1117-1137.

Stewart, M. J. (1993) 'The Effect of Advertising Bans on Tobacco Consumption in OECD Countries', International Journal of Advertising, 12, pp.155-180.

Taylor, W. E. and Zona, J. D. (1997) 'An Analysis of the State of Competition in Long-Distance Telephone Markets', Journal of Regulatory Economics, 11, pp.227255. 
Tylee, J. (2003) 'Gallaher Unleashes Blitz for B\&H Silver to beat Tobacco Ban', Campaign, February $7^{\text {th }}, 1$.

Zweifel, P. and Crivelli, L. (1996) 'Price Regulation of Drugs: lessons from Germany', Journal of Regulatory Economics, 10, pp.257-273.

Word Count: 2, 773 